Article

\title{
Raw materials based on fly ash of eggs shell and Algerian sand dune (southern west of Algeria) for synthesis of environmentally cementitious materials: synthesis and characterization
}

\author{
Abdelghani Brahimi*1, Mourad Meghachou ${ }^{1}$, Hichem Abbad ${ }^{1}$, AbdelkaderRahmouni*2, \\ Fatima Zohra Zeggai ${ }^{2,3}$, Bachari Khaldoun ${ }^{3}$,Redouane Chebout ${ }^{3}$ and Mohammed Belbachir ${ }^{2}$ \\ 1 Department of Civil Engineering, Laboratory of Civil Engineering and Environment, Djillali Liabes \\ University, 22000 Sidi Bel-Abbes, Algeria. \\ 2 Department of Chemistry, Laboratory of Polymer Chemistry (LCP)-University of Oran1 Ahmed

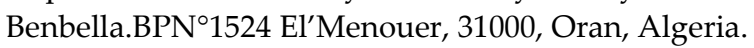 \\ 3 Centre de Recherche Scientifique et Technique en Analyses Physico-chimiques (CRAPC), BP \\ 38Bou-Ismail-RP 42004, Tipaza, Algeria. \\ E-mail :ramaek23@yahoo.frTel :+ 213773157287
}

Abstract: The dominant cementitious materials based on fly ash are attracting attention in the global research community because of their properties that affect their performance such durability, mechanical properties, physical-chemical properties and reduction of carbon dioxide $\left(\mathrm{CO}_{2}\right)$. The present study relates to an economical and ecofriendly method, capable of being implemented in two simples steps. Method of preparing new green cementitious material based on eggs shell rich in calcium ( $\mathrm{Ca}$ ) and sand dune (southern of Algeria) rich in silica $\left(\mathrm{SiO}_{2}\right)$. The first step of preparing $\mathrm{SiO}_{2}$ from sand include sand obtained with size less than 100 microns by washing with an alkali and hydrochloric acid $(\mathrm{HCl})$ followed by washing with distilled water. The sand particles are then dried at room temperature. Further, the second step includes a preparation of fly ash of eggs shell with particles size in a range of 100 to 120 microns. The method includes mixing the silicon dioxide $\left(\mathrm{SiO}_{2}\right)$ and fly ash particles in predefined ratio, heating the mixture at a temperature for predefined time. Cementitious material was finally obtained. The optimal mix has a compressive strength of $49.71 \mathrm{Mpa}$, is the most flexible $(\mathrm{E}=2.63 \mathrm{GPa}$ and ductile $(\varepsilon r=65.42 \%)$.The chemical and physical properties of the prepared cementitious material were analyzed by several technics such as XRF, XRD and SEM.

Keywords: fly ash; geopolymer; silicon dioxide; sodium silicate; sand dune; egg shell

\section{1-Introduction}

In the recent years, there has been a higher awareness on the hazardous solid waste generation and its impact on human health, as well as an increased focus on the environmental consequences of waste disposal. This forces the industry to find alternative ways to reuse waste materials. One solution is to reuse the waste materials to create geopolymers as an alternative 
to cement[1-2]. Sand dune is any accumulation of sand grains shaped into a mound or ridge by the wind under the influence of gravity [3]. Sand dunes are comparable to other forms that appear when a fluid moves over a loose bed, such as subaqueous "dunes" on the beds of rivers and tidal estuaries and sand waves on the continental shelves beneath shallow seas [4]. Dunes are found wherever loose sand is windblown: in deserts, on beaches, and even on some eroded and abandoned farm fields in semiarid regions [5]. The Algerian Sahara is made up of nine strictly Saharan wilayas (Adrar, Béchar, Biskra, El Oued, Ghardaïa, Illizi, Ouargla, Tamanrasset and Tindouf) as well as a predominantly Saharan wilaya (Laghouat) and three have minority Saharan areas in the south (Djelfa, El Bayadh and Naama) [6].The Sahara Desert covers almost $90 \%$ of the Algerian territory; it is crossed by "ergs" (sand dunes).Lime mortars are believed to have been developed in ancient Egypt[7]. These generally harden and gain strength by the evaporation of water and the absorption of carbon dioxide from the atmosphere. This results in the gradual conversion of the lime into calcium carbonate, commonly known as air lime [8]. Cementitious materials contribute to the properties of hardened concrete through hydraulic or pozzolanic activity. Typical examples are fly ashes, slag cement (ground, granulated blast-furnace slag), and silica fume[9]. These can be used individually with portland or blended cement or in different combinations. Cementing materials are often added to concrete to make concrete mixtures more economical, reduce permeability, increase strength, or influence other concrete properties [10]. Fly ash, the most commonly used pozzolanic in concrete, is a by-product of thermal power generating stations. Commercially available fly ash is a finely divided residue that results from the combustion of pulverized coal and is carried from the combustion chamber of the furnace by exhaust gases. Slag Cement, formerly referred to as ground, granulated blast-furnace slag, is a glassy, granular material formed when molten, iron blast-furnace slag is rapidly chilled typically by water sprays or immersion in water and subsequently ground to cement fineness[11]. Slag cement is hydraulic and can be added to cement as a cementitious material [12]. Silica fume, also called condensed silica fume or micro-silica, is a finely divided residue resulting from the production of elemental silicon or aluminum-silicon alloys that is carried from the furnace by the exhaust gases. Silica fumes, with or without fly ash or slag, is often used to make high-strength concrete [13]. Cementitious materials for concrete are fine mineral powders. When these materials are mixed with water, they react chemically to form a strong rigid mass that binds aggregate particles together to make concrete [14]. In recent years, the dominant cementitious materials have been industrial by products such as fly ash. The experimental proposed of geopolymers synthesized taking place in (Scheme.1). Fly ash of eggs (FAES) is collected from the exhaust flow of furnaces burning finely ground coal. The finer fractions are used as a portland cement extender. FAES reacts with sodium hydroxide $(\mathrm{NaOH})$ in the presence of water to form cementing compounds consisting of sodium silicate hydrate. This reaction is called pozzolanic and FAES may be described as a synthetic pozzolanic. The hydration of portland cement produces significant amounts of calcium hydroxide, which does not contribute to the strength of the hardened cement paste [15]. The combination of FAES and sand dune rich in silicon and aluminum is a practical means of using FAES and converting calcium to a cementing compound [16]. This paper reports the investigation 
conducted on the effect of fly ash of eggs shell and sand dune on the properties of geopolymers synthesized. Geopolymers were made with sand dune and various percentages of fly ash (FAES). The main objective of this work is the valorization of sand dune (southern west of Algeria) and fly ash of eggs shell for synthesis of eco-friendly cement which owns good mechanical and physical-chemical properties. The composition, structure, microstructure and texture of the fly ash ,sand dune and geopolymers (cementitious materials) were investigated using several methods such as XRD, XRF and SEM. Some properties of geopolymers derived from fly ash and sand dune have also been studied.

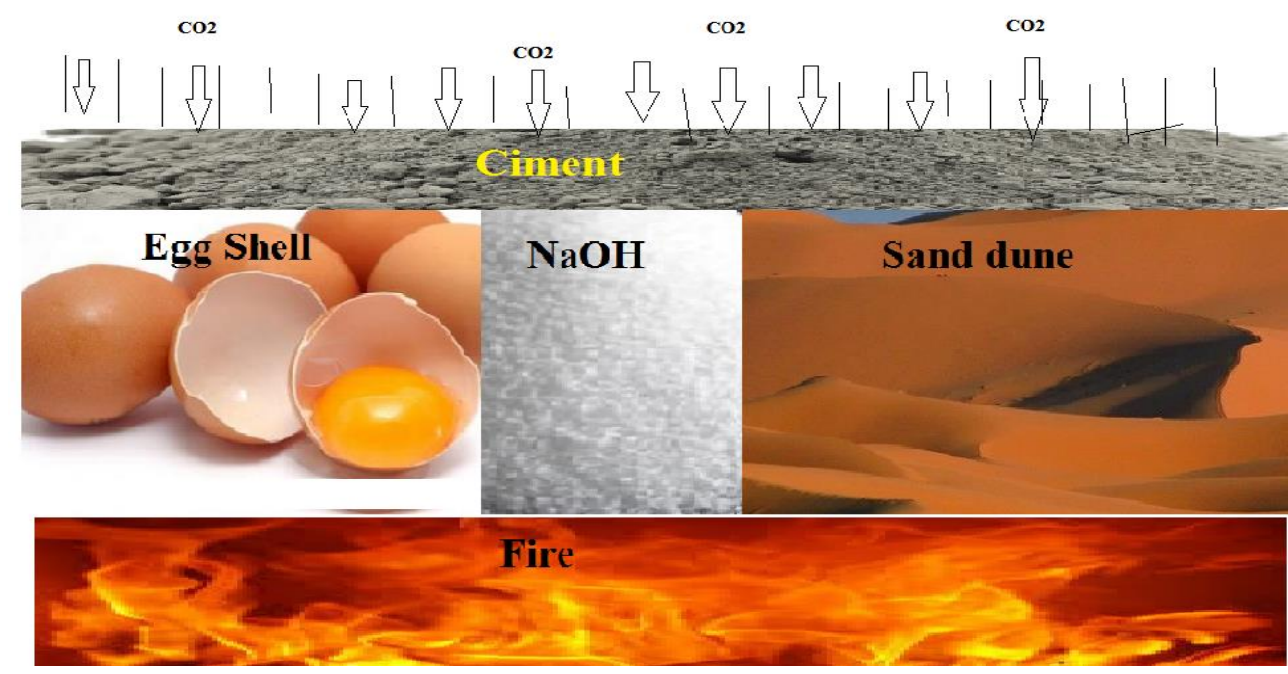

Scheme.1. proposed materials for synthesis of different geopolymers (GPs).

\section{Experimental section}

\subsection{Materials and methods}

A-The silica sand in these experiments was from dune sand (west south of Algeria).For the first part of the experiment, $100 \mathrm{~g}$ of dry sand have been processed by $200 \mathrm{ml}$ of hydrochloric acid for 30 minutes at ambient temperature. For the second part of experiment, all leaching tests were conducted in a $250 \mathrm{ml}$ glass beaker placed on a heater, with a magnetic stirrer having a controller unit. When the required temperature $\left(80^{\circ} \mathrm{C}\right)$ of the beaker contents $(100 \mathrm{ml}$ of acid) was reached, approximately $30 \mathrm{~g}$ of dry sand were added into the beaker, while the contents of the beaker has been stirred at a constant speed of $200 \mathrm{rpm}$. The beaker was covered to prevent losses by evaporation. From leaching solution an amount of sample of the reaction mixture was taken out at pre-determined time intervals, filtered, repeatedly washed with distilled water to remove any unspent acid and then dried at $110^{\circ} \mathrm{C}$ for one hour. All experiments were carried out in duplicate and sometimes repeated again and the mean values are reported. The chemical composition of the silica sand sample used in this study was determined before leaching, using XRF analysis. The results are presented in (Table.1).

Table 1.Chemical composition of different form of Sand dune (SD). 


\begin{tabular}{ccccc}
\hline $\begin{array}{c}\text { Oxide } \\
(\mathbf{w} \%)\end{array}$ & SD-Raw & SD-HCl & Water glass & Silicone \\
\hline $\mathrm{SiO} 2$ & 90.04 & 90.83 & 96.99 & 99.16 \\
\hline $\mathrm{Al} 2 \mathrm{O} 3$ & 8.56 & 7.45 & 1.61 & 0.31 \\
\hline $\mathrm{Fe} 2 \mathrm{O} 3$ & 0.29 & 0.29 & 0.29 & 0.20 \\
\hline $\mathrm{CaO}$ & 0.56 & 0.52 & 0.21 & 0.15 \\
\hline $\mathrm{MgO}$ & 0.00 & 0.00 & 0.00 & 0.00 \\
\hline $\mathrm{SO} 3$ & 0.35 & 0.32 & 0.65 & 0.07 \\
\hline $\mathrm{K} 2 \mathrm{O}$ & 0.00 & 0.01 & 0.00 & 0.03 \\
\hline $\mathrm{Na} 2 \mathrm{O}$ & 0.02 & 0.01 & 0.00 & 0.02 \\
\hline $\mathrm{P} 2 \mathrm{O} 5$ & 0.06 & 0.09 & 0.00 & 0.02 \\
\hline $\mathrm{TiO} 2$ & 0.08 & 0.09 & 0.04 & 0.00 \\
\hline $\mathrm{Cr} 2 \mathrm{O} 3$ & 0.00 & 0.00 & 0.00 & 0.00 \\
\hline $\mathrm{Mn} 2 \mathrm{O} 3$ & 0.00 & 0.00 & 0.00 & 0.01 \\
\hline $\mathrm{ZnO}$ & 0.00 & 0.00 & 0.00 & 0.00 \\
\hline $\mathrm{SrO}$ & 0.02 & 0.01 & 0.01 & 0.03 \\
\hline $\mathrm{CO} 2$ & 0.00 & 0.00 & 0.00 & 0.20 \\
\hline $\mathrm{LOI}$ & 0.02 & 0.38 & 0.00 & \\
\hline
\end{tabular}

B-A fly ash sample was collected from a eggs shell as raw material washed firstly with distilled water and then by acidic solution $(\mathrm{HCl} 1 \mathrm{M})$ to remove impurity and minimize rate of limine $(\mathrm{CaO})$. After drying and when all moister was removed then this sample takes for calcination under 700 to $850^{\circ} \mathrm{C}$ then dried at $25^{\circ} \mathrm{C}$. The XRF analysis was conducted to characterize the fly ash sample. The results of the XRF test are shown in (Table 2). It is clear that the sample is rich in limine and silica making it a suitable raw material for the geopolymerisation process. The fly ash particle size was below $100 \mu \mathrm{m}$, so there was no need for any pretreatment. Chemical composition of fly ash was determined by X-ray fluorescence analysis, the results of which are displayed in Table 1. It is obvious that the major element of the investigated fly ash was $\mathrm{CaO}(63.69 \%)$.

C-The sodium silicate called water glass $\left(\mathrm{Na}_{2} \mathrm{SiO}_{3}\right)$ was synthesized in our laboratory (laboratory of polymer chemistry at oran1 university of Algeria) by using $100 \mathrm{~g}$ of sand dune washed with acidic solution $(\mathrm{HCl} 1 \mathrm{M})$ and dried at $25^{\circ} \mathrm{C}$ then mixed with $200 \mathrm{~g}$ of sodium hydroxide $(\mathrm{NaOH} 13 \mathrm{M})$. The mixture was fused using a platinum crucible using in an electrical-fired furnace at $850{ }^{\circ} \mathrm{C}$ for one hours and a heating rate of $5^{\circ} \mathrm{C} / \mathrm{min}$. The melt was left to cool and solidify in the crucible. our procedure managed to synthesize 70 grams of sodium silicate nanomaterials (water glass), it is white powder, then was dried at $25^{\circ} \mathrm{C}$ for microstructural, chemical and mineralogical analysis.

\subsection{Methods}

All reagents in this work were of analytical grade and used as received without further purification. $\mathrm{NaOH}$ and $\mathrm{HCl}(36 \%)$ were used as initiator from sigma Aldrich (French). The sand dune used in this work came from a quarry located in Naama (southern west of Algeria).

\subsection{Synthesis of the geopolymers (GPS)}

Method of preparing new green cementitious material (geopolymers) based on eggs shell rich in calcium $(\mathrm{Ca})$ and sand dune (southern of Algeria) rich in silica $\left(\mathrm{SiO}_{2}\right)$ based on two steps. The first step of preparing $\mathrm{SiO}_{2}$ from sand include sand obtained with size less than 100 microns by washing with an alkali and hydrochloric acid $(\mathrm{HCl})$ followed by washing with distilled water. The sand particles are then dried at room temperature. Further, the second step includes a preparation of fly ash of eggs shell with 
particles size in a range of 100 to 120 microns. Fly ash called (FAES) classified as (F) washed with acidic solution $(\mathrm{HCl} 1 \mathrm{M})$ to eliminate impurity and minimize the rate of calcium and limine as producers of carbon dioxide $\left(\mathrm{CO}_{2}\right)$, then calcined at 700 to $900^{\circ} \mathrm{C}$ .The method includes mixing the silicon dioxide $\left(\mathrm{SiO}_{2}\right)$ and fly ash particles in predefined ratio, heating the mixture at a temperature for predefined time. Finally, we prepare four samples of geopolymers (cements) for comparison purposes as shown in (Table 3). The resulting mixture was poured into a mould and left at room temperature in 24 hours, then placed in an oven at $80{ }^{\circ} \mathrm{C}$ for 24 hours. The results of the XRF test are shown in (Table 4). It is clear that the sample is rich in limine and silica making it a suitable raw material for the geopolymerisation process.

Table 2.composition of different form of eggs shell and fly ash obtained byFluorescence spectroscopy(XRF).

\begin{tabular}{ccccc}
\hline & & & & \\
Oxides(w\%) & ES-Raw & ES-HCl & Fly ash & Fly ash-NaOH \\
\hline $\mathrm{SiO} 2$ & 0.240 & 0.060 & 0.002 & 0.060 \\
\hline $\mathrm{Al} 2 \mathrm{O} 3$ & --- & 0.040 & --- & 0.030 \\
\hline $\mathrm{Fe} 2 \mathrm{O} 3$ & 0.040 & 0.010 & 0.007 & 0.010 \\
\hline $\mathrm{CaO}$ & 61.130 & 35.390 & 63.69 & 36.230 \\
\hline $\mathrm{MgO}$ & 0.500 & 0.520 & 0.570 & 0.530 \\
\hline $\mathrm{SO} 3$ & 0.100 & 0.090 & 0.090 & 0.090 \\
\hline $\mathrm{K} 2 \mathrm{O}$ & 0.042 & 0.040 & 0.060 & 2.950 \\
\hline $\mathrm{Na} 2 \mathrm{O}$ & 0.085 & 2.920 & 0.190 & 0.210 \\
\hline $\mathrm{P} 2 \mathrm{O} 5$ & 0.020 & 0.250 & 0.280 & 0.230 \\
\hline $\mathrm{TiO} 2$ & 0.017 & --- & 0.020 & --- \\
\hline $\mathrm{Cr} 2 \mathrm{O} 3$ & 0.006 & --- & 0.010 & --- \\
\hline $\mathrm{Mn} 2 \mathrm{O} 3$ & 0.006 & --- & 0.010 & --- \\
\hline $\mathrm{ZnO}$ & 0.005 & 0.004 & 0.010 & 0.010 \\
\hline $\mathrm{SrO}$ & 0.025 & 0.012 & 0.030 & 0.010 \\
\hline $\mathrm{CO} 2$ & --- & 59.800 & --- & 58.640 \\
\hline $\mathrm{LOI}$ & 38.600 & 60.650 & 34.950 & 59.650 \\
\hline
\end{tabular}

Table 3.Procedure for synthesized geopolymers (GPs).

\begin{tabular}{|c|c|c|c|c|c|c|c|}
\hline Geopolymers (GPs) & \multicolumn{7}{|c|}{ Mass (g) ratio } \\
\hline GP-1 : Na2SiO3, FAES , NaOH ,H2O & & & 3.00 & $: \quad 1.00$ & : & & 25 \\
\hline GP-2 : $\mathrm{Na}_{2} \mathrm{SiO}_{3}$, FAES , NaOH $, \mathrm{SiO}_{2}, \mathrm{H} 2 \mathrm{O}$ & 1.75 & & 3.00 & 1.00 & $:$ & $0.5:$ & 2.25 \\
\hline GP-3 : $\mathrm{Na}_{2} \mathrm{SiO}_{3}$, FAES , $\mathrm{NaOH}, \mathrm{Al}_{2} \mathrm{O}_{3}, \mathrm{H}_{2} \mathrm{O}$ & 1.75 & & $: 3.00$ & $: 1.00$ & $: 0.5$ & : & 2.25 \\
\hline GP-4 : $\mathrm{Na}_{2} \mathrm{SiO}_{3}$, FAES , $\mathrm{NaOH}, \mathrm{Fe}_{2} \mathrm{O}_{3}, \mathrm{H}_{2} \mathrm{O}$ & 1.75 & & 3.00 & $: \quad 1.00$ & $:$ & 0.5 & 2.25 \\
\hline GP-5 : $\mathrm{Na}_{2} \mathrm{SiO}_{3}$, FAES , $\mathrm{NaOH}, \mathrm{Fe}_{2} \mathrm{O}_{3}, \mathrm{H}_{2} \mathrm{O}$ & 1.75 & : & 3.00 & 1.00 & $:$ & 0.5 & 2.25 \\
\hline GP-7 : $\mathrm{Na}_{2} \mathrm{SiO}_{3}$, FAES , $\mathrm{NaOH}, \mathrm{Fe}_{2} \mathrm{O}_{3}, \mathrm{H}_{2} \mathrm{O}$ & 1.75 & . & 3.00 & 1.00 & $:$ & 0.5 & 2.25 \\
\hline
\end{tabular}

\section{Results and discussion}

Cementitious materials in general have been synthesized using fly ash of eggs shell actived by alkali solution and silicate sodium from sand dune (Southern of Algeria). Many researchers stated that geopolymers are good candidates for water absorber due to their microstructure [17]. Moreover, geopolymer specimen synthesized with $\mathrm{NaOH}$ molar ratio shows higher water storage capacity [18]. X-ray diffraction proved geopolymer formation. On the basis of this analysis the prepared geopolymer confirmed quartz as the main component, hematite, calcite ferrite and mullite are observed and it can be stated is responsible for geopolymer networking. Thus, it is confirmed that only the amorphous part of these reagents present reactivity under alkaline conditions, acting as a geopolymer precursor and substitute for metakaolin. 


\subsection{Analysis of raw material}

\subsubsection{Analysis of different form of sand dune}

The most common constituent of our sand dune is silica $\left(\mathrm{SiO}_{2}\right)$, usually in the form of quartz, which, because of its chemical inertness and considerable hardness, is resistant to weathering. The composition of sand is highly variable, depending on the local rock sources and conditions. X-ray Fluorescence (XRF) is the best technique to detect even the minor concentrations of elements in a sample. Results are shown in (Table 1).

X-Ray Diffraction (XRD) on powder is a technique commonly used for the identification of crystalline phases in a material. The diffraction lines of the compound, specific to each crystal structure, indicate the nature of the phases in the compound. The diffractometer used is a Bruker D8 Focus with a ray tube $X$ with copper anticathode $\lambda_{\mathrm{K} \alpha 1}=1.5406 \AA$ and $\lambda_{\mathrm{K} \alpha 1}=1.5445 \AA$. The geometry is of the Bragg Brentano type, and a $\theta-2 \theta$ assembly is used: in this configuration, the incident beam makes an angle $\alpha$ with the sample surface and the detector is in position $2 \theta$ with respect to the $\beta$-incident beam, as indicated in all figures [19]. In the case of our diffractometer, the detector and the sample are mobile and the source is stationary. The Intensity $2 \theta$ experimental diagram shows diffraction lines when the plans satisfy Bragg's law:

$$
2 \mathrm{dhk} 1 \sin \theta \mathrm{hk} 1=\mathrm{n} \lambda
$$

Where dhkl is the inter-sectional distance (ie distance between two crystallographic planes); $\theta$ is the Bragg angle; $n$ is the diffraction order (integer); $\lambda$ is the wavelength of $\mathrm{X}$-rays.

According to (Table.1), we show that sand dune is very rich in silica in different forms $\left(90.04^{\circ}\right.$ $\mathrm{C}$ to $99.16 \%$ ). This sand has a low concentration of alumina even lower concentration of other oxides such as the hematite, the free rutile, the butschliite, zincite, calcite and magnetite, which were also found in the raw material. In order to determine the parameters and the structure of the crystal lattice of our sand dune samples, we have used the X-ray diffraction which turns out to be the only technique for the determination of these parameters. The XRD spectrum of different of sand dune is shown in (Figure 1.) and we observe the appearance of all peaks related to the presence of alpha-quartz in our sand sample, confirming the high crystallinity. In all figures we observe the appearance of all peaks relating to the presence of alpha-quartz in our sand sample, confirming the increased crystallinity. According to these results, we attest other phases than quartz (minor quantities).This result confirms the latest result found by XRF analysis [20]. The crystallographic parameters of sand have been determined through X-ray diffraction analysis and silica sand has a hexagonal crystal system and crystallographic parameters are: $a=b=4.6010 \mathrm{~A}, \mathrm{c}=5.3896 \mathrm{~A}$. 

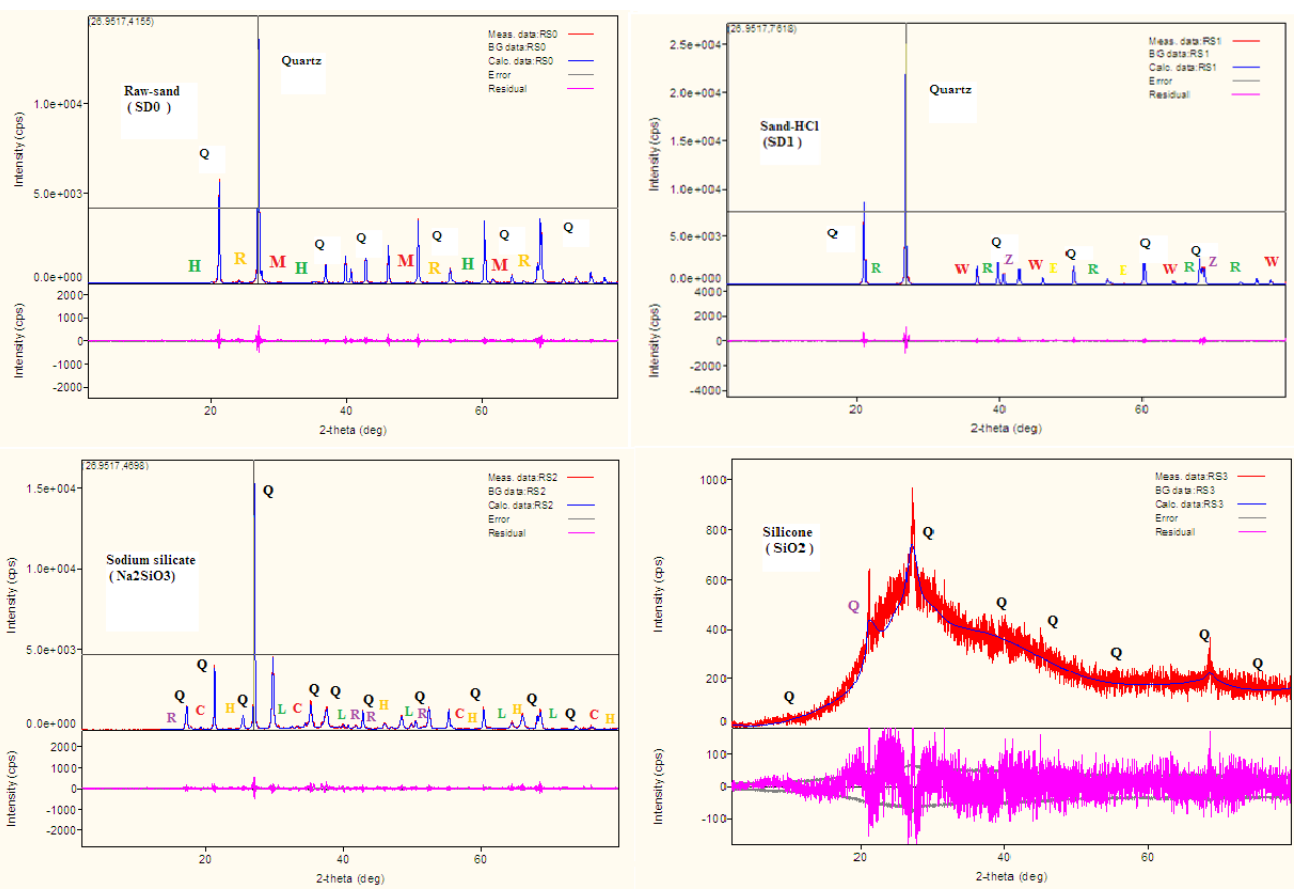

Figure 1. .XRD patterns of raw sand,sand treated with $1 \mathrm{M} \mathrm{HCl}$,sodium silicate $\mathrm{Na}_{2} \mathrm{SiO}_{3}$ and silicon dioxide $\mathrm{SiO}_{2}$.

X-ray patterns of the synthesized silicate glass (Figure.1) shows a characteristic broad diffuse peak at $2 \theta=18-40^{\circ}$ due to their X-ray amorphous and complex structure of the silicates [21]. Furthermore, there is no crystalline phase peak in XRD patterns due to the silicate compositions. However, crystalline phases peaks appeared in the XRD pattern of the ground mixture, owing to the quartz sand $\left(\mathrm{SiO}_{2}\right)$ at $2 \theta=21,27,43,60^{\circ}$.

The sodium silicate glass synthesis in this study is XRD amorphous, with a dense surface morphology. The glass is enriched in $\mathrm{Si}$ than $\mathrm{Na}$ and $\mathrm{Al}$ and the average atomic composition is homogeneous throughout the entire glass [22]. It is further established that, the synthesized glass has a $\mathrm{SiO}_{2} / \mathrm{Na}_{2} \mathrm{O}$ molar ratio of 0.55 and the possible composition is $\mathrm{Na}_{2} \mathrm{SiO}_{3}$. Given this less molar ratio $\mathrm{SiO}_{2} / \mathrm{Na}_{2} \mathrm{O}$ and this composition, it can be concluded that the synthesized silicate has a homogenous structure which are associated with less molar ratio and the less $\mathrm{Al}_{2} \mathrm{O}_{3}$ contents respectively [23]. A study by other research on sodium silicate binder has also reported a broad halo peak registered between $2 \theta=16^{\circ}$ and $2 \theta=30^{\circ}$, and it was attributed to silicate gel, lacking long-range order [24]. Another Alkali-silicate gel XRD analysis have also observed a strong reflection at $2 \theta=26^{\circ}$ for all silicate gel with various $\mathrm{Na}_{2} \mathrm{O}$ contents [25].

The raw materials used in this work are sand dune (Southern of Algeria) rich in silicon .Silica is the principal constituent of the sand moulds. Granular particles of silica sand, principally comprises $50-95 \%$ of the total material of a molding mixture [26]. They differ as per their physical and chemical properties e.g. average grain size, their shape and distribution, their chemical composition, their refractoriness and thermal stability [27]. To study the microstructure of different forms of sand, we examine powder sample and we used scanning electron microscopy (SEM) to observe and describe the internal structure. The images of grains sand dune of different forms are shown in (figure 2).The sand grains may be rounded angular or sub-angular [28]. The SEM micrographs show the synthesized glass surface morphology characterized by a dense morphology with cracks in the other hand our micrograph show the glass surface characterized by chemical trace, then we suggest that is sodium $(\mathrm{Na})$ of the silicate sodium used [29]. 

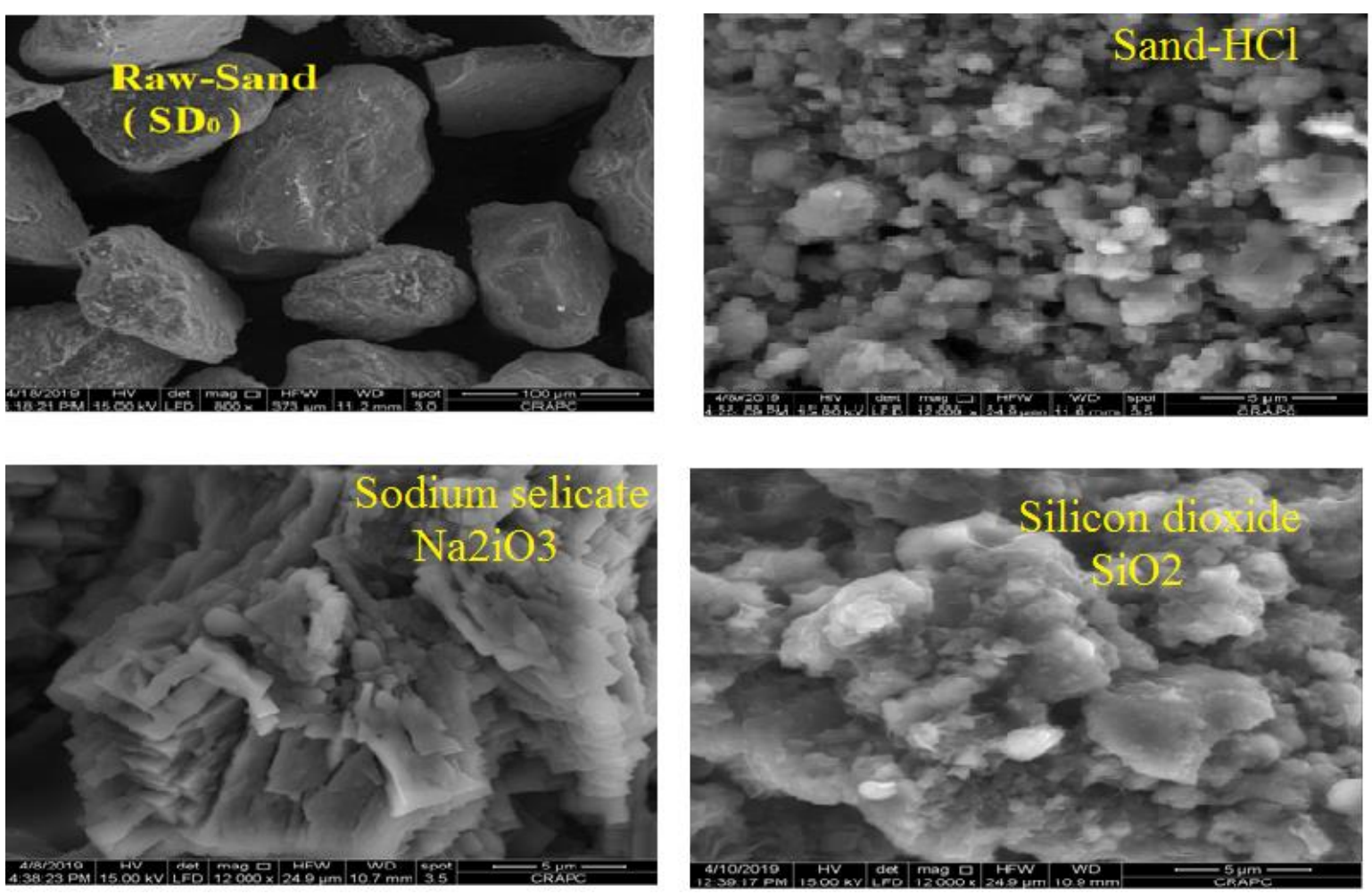

Figure 2.SEM micrographs of the different forms of sand dune (southern of Algeria).

\subsubsection{Analysis of different form of eggs shell and fly ash}

Fly ash consists of minerals, which include silicon, aluminum, iron, calcium, magnesium and traces of titanium and organic matter, such as carbon. Elemental composition of different form of eggshell and fly ash were shown in (Table 2.).CaO content increased from $61.13 \%$ in raw eggshell to $63.69 \%$ in calcined eggshell by XRF analysis. From this result, it showed the $\mathrm{CaCO}_{3}$ had approximately converted to $\mathrm{CaO}$ [30]. Additionally, other chemical compositions contain in the calcined eggshell were $\mathrm{MgO}$ $(0.50 \%), \mathrm{Al}_{2} \mathrm{O}_{3}(0.04 \%), \mathrm{SrO}(0.025 \%)$ reported that the percentage of $\mathrm{CaO}$ in calcined eggshell was $97.4 \%$, while the percentage of other chemical compositions were $0.50 \%$ for $\mathrm{MgO}, 0.50 \%$ for $\mathrm{P}_{2} \mathrm{O}_{5}, 0.02 \%$ for $\mathrm{SO}_{3}, 0.10 \%$ for $\mathrm{K}_{2} \mathrm{O}, 0.042 \%$ for $\mathrm{SrO}, 0.04 \%$ for $\mathrm{Fe}_{2} \mathrm{O}_{3}$, and $0.00 \%$ for $\mathrm{CuO}$ [31]. Results showed that $\mathrm{CaO}$ was the most abundant element in the eggshells as the $\mathrm{CaCO}_{3}$ was the main presence in the eggshell. Small amount of other compositions in the eggshell considered that the waste eggshell could be natural carbonate-based material.

XRF analyses provide highly precise, and if calibrated properly, accurate data on the bulk chemistry of a sample. The chemical data can be converted into forms more applicable to geoscientists and engineers, providing mineral compositions and reservoir properties [32]. The chemical compositions characteristics of the raw eggshell, calcined eggshell and fly ash of eggs shell were determined using XRF.XRF analysis of raw egg shell and fly ash of egg shell and actived fly ash were presented in (Table 2).The egg-shell consists of several mutually through-growing layers of $\mathrm{CaCO}_{3}$ [33]. Powder diffraction analysis nowadays may include application of different diffraction geometries and analysis of peak positions, intensities and widths. Different kinds of eggshells in the powder form or 
as a whole from both sides of the shell were examined by diffractometer method. This makes possible a complete XRD-ray analysis phase analysis, structure crystallite size and texture analysis [34]. In our present work we have tried to perform more complete diffraction analysis of different forms of egg-shells.XRD analysis of raw eggshell $\left(\mathrm{CaCO}_{3}\right)$ and fly ash eggshell $(\mathrm{CaO})$ were presented in (Figure.3).For the raw eggshell, main peak was observed. These peak values were the characteristics of $\mathrm{CaCO}_{3}$ and the peak for the fly ash eggshell characteristics of calcium oxide (Figure 3.).The XRD result of sample of eggs shell leaching with $\mathrm{HCl}(1 \mathrm{M})$ summarized by (figure 3 ) exhibit characteristic diffraction at an angle $2 \theta=23.101^{\circ}$ corresponds to a $\mathrm{d}(001)$ spacing of $3.847^{\circ}, 2 \theta=29.466^{\circ}$ which corresponds to a (d) spacing of $3.028 \mathrm{~A}^{0}, 2 \theta=36.039^{0}, 39.439^{0}, 43.244^{0}, 47.213^{0}, 47.625^{0}$, $48.615^{0}, \ldots .65 .010^{0}$ witch correspond to the calcium carbonate $\left(\mathrm{CaCO}_{3}\right)$. The XRD result of sample of eggs shell fly ash treated with sodium hydroxide $10 \mathrm{M}(\mathrm{ES}-\mathrm{NaOH})$ represent by (figure.3) exhibit characteristic diffraction witch correspond to the calcium carbonate $\left(\mathrm{CaCO}_{3}\right)$ cited in figure1. Diffractogram as well exhibit characteristic diffraction at an angle $2 \theta=31.516^{\circ}$ the latter corresponds after conversion to a $\mathrm{d}(001)$ spacing of $2.836 \mathrm{~A}^{0}$. The second order diffraction is at $2 \theta=43.244^{0}$ which corresponds to a $\mathrm{d}$ spacing of $2.090 \mathrm{~A}^{\mathrm{o}}$ and another's peaks at $2 \theta=54.233^{\circ}, 55.992^{\circ}, 95.095^{\circ}, 11.302^{0}$ correspond to potassium calcium carbonate $\mathrm{K}_{2} \mathrm{Ca}\left(\mathrm{CO}_{3}\right)_{2}$ mineral name (Butschliite, syn).In diffractogram we found characteristic diffraction at an angle $2 \theta=18.108^{0}$ correspond after conversion to a $\mathrm{d}(001)$ spacing of $4.895 \mathrm{~A}^{0}$ and $2 \theta=34.170^{\circ}, 36.689^{0}, 50.8970 \ldots . .86 .453^{0}$ which correspond to the calcium hydroxide $\mathrm{Ca}(\mathrm{OH})_{2}$ or portlandite syn.

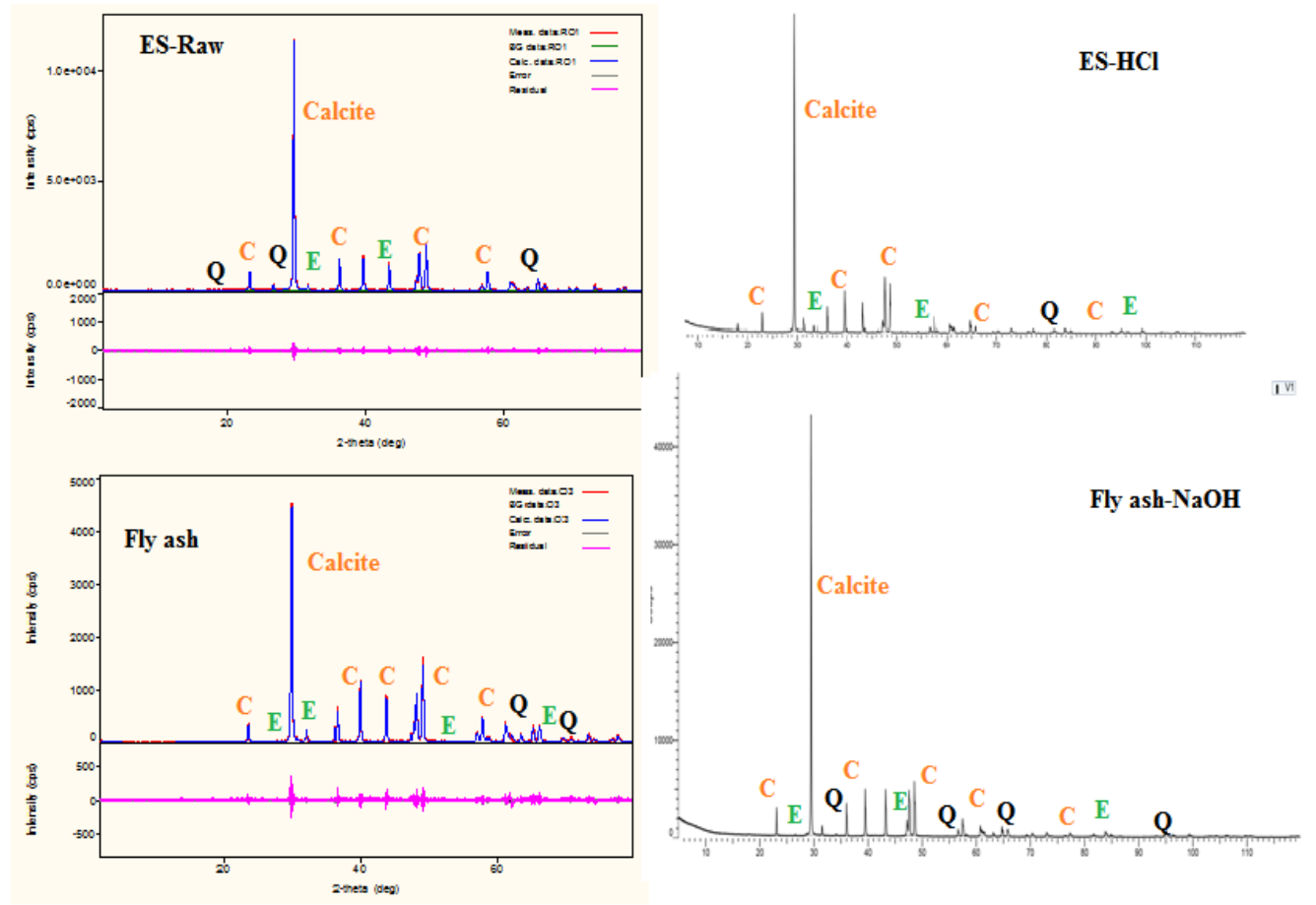

Figure 3. .XRD patterns of different form of eggs shell and fly ash.

To study the microstructure of different forms of eggs shell and fly ash, we examine powder samples using scanning electron microscopy (SEM) to observe and describe the internal (versus surface) structure and orientation of the calcium carbonate crystals . 
Microstructure analysis can sometimes determine which processes caused these surface textures. The most raw egg shell has a relatively smooth external surface as show in (figure.4) (Egg shell raw).The scale in this figure is used to check the sizes of the microstructure features, since the photos' aspect ratios were preserved.SEM micrographs shown in (figure 4) show the morphology changes in the different eggs shell and fly ash samples compared to fly ash actived (FAES-NaOH). The micro structural study of the samples reveals that they have particles of different size and shapes, porosity, the dispersion of the egg shell. Also, in this matrix we observed more important phases for exemple acicular crystals and calcite. In photomicrograph there is the presence a unique calcite crystal, i.e. a particle of filler present in the matrix is depicted. Already, in photomicrographs are observed euhedral calcite crystals. Probably, this is the original calcite as filler because eggs shell is rich in calcium as chown in (Table 2).The egg shells were retained in the phase is clearly observed in the microstructures. Based on the results of research that has been done that shell contains calcium oxide $(\mathrm{CaO})$.The morphological imaging of SEM (Scanning electron microscopy) shows non-uniform materials and edges such as serrations, in addition to the size of calcium oxid still micrometer. Then from the analysis of EDS (Energy dispersy spectroscopy) the largest composition of egg shell and fly ash is calcium oxide $(\mathrm{CaO})$ of $61.13 \%$ (raw egg) , 36.23\% (fly ash-NaOH) and $63.69 \%$ ( fly ash) as shown in (Table 2).

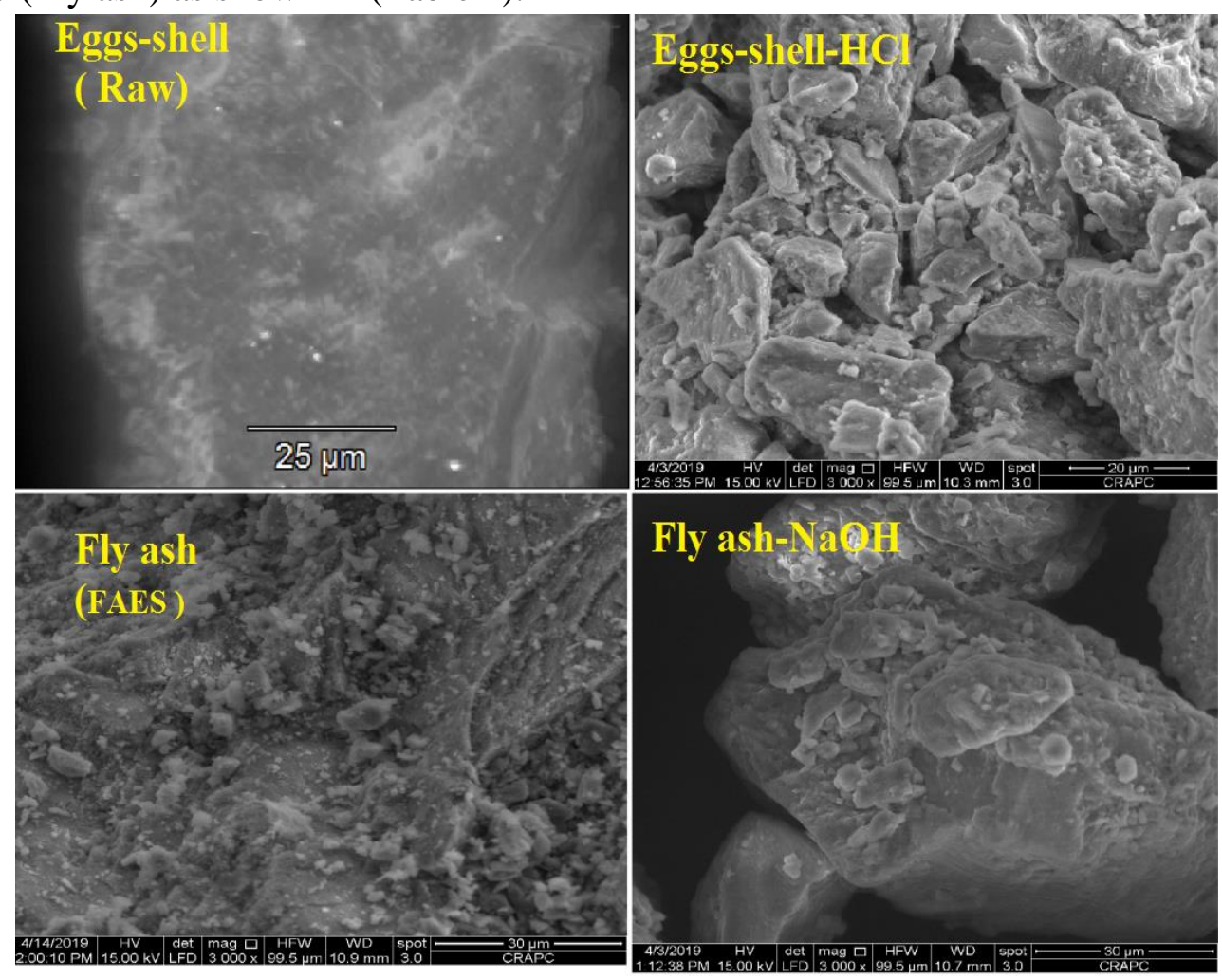

Figure 4.SEM micrographs of the different forms of eggs shell and fly ash egg shell (FAES: Fly ash eggs shell).

\subsubsection{Analysis of different form of prepared geopolymers (GPs)}

The most common constituent of geopolymers prepared is silica $\left(\mathrm{SiO}_{2}\right)$, usually in the form of quartz, which, because of its chemical inertness and considerable hardness, is resistant to weathering. The composition of geopolymers is highly variable, depending on the local sources and 
conditions [35]. X-ray Fluorescence (XRF) is the best technique to detect even the minor concentrations of elements in a sample as shown in (Table4).

\begin{tabular}{|c|l|l|l|l|l|l|l|l|}
\hline Samples & Water & & & & & & \\
$\begin{array}{l}\text { Oxide } \\
(\mathrm{w} \%)\end{array}$
\end{tabular}

Table 4.Chemical composition of fly ash water glass and different form of geopolymers. 


\begin{tabular}{|c|c|c|c|c|c|c|c|c|}
\hline $\mathrm{SiO} 2$ & 0.060 & 96.99 & 17.660 & 17.210 & 13.860 & 14.110 & 14.200 & 14.310 \\
\hline $\mathrm{A} 12 \mathrm{O} 3$ & 0.030 & 1.51 & 0.000 & 0.010 & 14.790 & 10.84 & 0.030 & 15.720 \\
\hline $\mathrm{Fe} 2 \mathrm{O} 3$ & 0.010 & 0.29 & 0.080 & 0.110 & 0.040 & 0.060 & 8.070 & 7.650 \\
\hline $\mathrm{CaO}$ & 36.230 & 0.21 & 23.550 & 23.720 & 19.640 & 18.680 & 19.120 & 17.270 \\
\hline $\mathrm{MgO}$ & 0.530 & 0.00 & 0.210 & 0.220 & 0.210 & 0.190 & 0.170 & 0.200 \\
\hline $\mathrm{SO} 3$ & 0.090 & 0.65 & 0.110 & 0.160 & 0.100 & 0.120 & 0.160 & 0.140 \\
\hline $\mathrm{K} 2 \mathrm{O}$ & 2.950 & 0.00 & 0.060 & 0.060 & 0.040 & 0.050 & 0.050 & 0.040 \\
\hline $\mathrm{Na} 2 \mathrm{O}$ & 0.210 & 0.00 & 30.450 & 30.570 & 26.030 & 31.200 & 29.900 & 26.170 \\
\hline $\mathrm{P} 2 \mathrm{O} 5$ & 0.230 & 0.00 & 0.100 & 0.100 & 0.080 & 0.090 & 0.090 & 0.080 \\
\hline $\mathrm{TiO} 2$ & - & 0.04 & 0.020 & 0.030 & 0.020 & 0.020 & 0.040 & 0.030 \\
\hline $\mathrm{Cr} 2 \mathrm{O} 3$ & - & 0.00 & 0.002 & 0.004 & 0.002 & - & 0.020 & 0.020 \\
\hline $\mathrm{Mn} 2 \mathrm{O} 3$ & -- & 0.00 & 0.003 & 0.004 & 0.003 & - - - & 0.020 & 0.020 \\
\hline $\mathrm{ZnO}$ & 0.010 & 0.00 & 0.001 & 0.001 & -- & -- & 0.010 & 0.003 \\
\hline $\mathrm{SrO}$ & 0.010 & 0.01 & 0.012 & 0.013 & 0.010 & 0.010 & 0.010 & 0.010 \\
\hline $\mathrm{CO} 2$ & 58.640 & -- & - --- & -- & -- & -- & -- & -- \\
\hline LOI & 59.650 & 2.84 & 27.740 & 27.790 & 25.170 & 24.630 & 28.110 & 19.440 \\
\hline
\end{tabular}

Geopolymers are the best materials to prepare a ceramics materials. Preparation of our geopolymers are generally carried by an alkali silicate solution with a solid aluminosilicates such as sand dune, fly ash of eggs shell rich in calcium under effect of alkaline solution $(\mathrm{NaOH} 13 \mathrm{M})$. A study of the XRD patterns reveals obvious differences between the fly ash and geopolymer samples either in position of the amorphous hump or a forms of peaks from quartz (high or low) as shown in (Figure.5) .XRD patterns of fly ash based geopolymer shows that the geopolymer materials are prevailingly of X-ray amorphous character where the diffraction crystals were those of the original materials (mullite, hematite, limine, calcite and quartz). An amorphous hump is observed in the 
diffraction pattern between $2 \theta$ values of approximately $20^{\circ}$ to $69^{\circ}$, which could be due to the presence of amorphous glassy materials [36]. The diffractogram for the original fly ash changed when the ash was activated by alkaline solutions $(\mathrm{NaOH})$ [37]. The hump, which is attributed to the vitreous phase of the original ash, slightly shifted from $19-50^{\circ}$ to $20-69^{\circ}(2 \theta)$ values [38]. This change indicates the formation of an alkaline aluminosilicates hydrate gel which has been identified as the primary reaction product of geopolymerization reaction in the diffraction patterns of geopolymeric materials. The crystalline phases (quartz, mullite, hematite, calcite ) detected in the initial material remained apparently unaltered with activation [39]. For the geopolymer pattern, the original mineralogy of fly ash is not significantly modified which is in agreement with the literature. SEM micrograph shown in (Figures. 6 and 7) shown the morphology changes in the different geopolymers samples compared to fly ash. We observed that in all samples studied (GP-1,GP-2,GP-3 , GP-4,GP-5 and GP-7) the sodium silicate $\left(\mathrm{Na}_{2} \mathrm{SiO}_{3}\right)$ was observed as the majority product and more amount of fly ash was reacted during one hour of preparation. The microstructure of geopolymers was heterogeneous and the matrix was full of loosely structured fly ash grains of different sizes, except in sample (GP-2)as shown in (figure 7) when we observed good microstructure [40] . Numerous circular cavities belonging to fly ash particles are not appear in the gel and here, we suggest than considerable amount of sphere of fly ash are reacted and this result indicate an complete reaction in the system and explain that the fly ash show a high degree of reaction up to $78.93 \%$ after one hour. finaly, we concluded that the degree of reaction taking place in a geopolymer forming paste increases according to molar ration of $\left(\mathrm{SiO}_{2} / \mathrm{Al}_{2} \mathrm{O}_{3}\right)$ and reactivity of the fly ash rich in calcium (Ca) used as show in matrix (GP-2) [41]. Prepared geopolymers (GPs) show a large number of properties and are eco-building materials. Geopolymers concretes are formed by adding water to a geopolymer and we show that different geopolymers have a porous structures show in (figure 6). Molecules of water prevent gases for evolved and entrapped in the structure before the gel hardens. When water is added to FAES slurry in alkali activator solutions, geopolymer is formed. The number of compounds is known which produce gases on addition to geopolymers and are then entrapped to produce a microstructure in the hardened material. When water and geopolymer are mixed, chemical reactions liberate different gases which are entrapped in the structure especially carbon dioxid $\left(\mathrm{CO}_{2}\right)$.Because it is highly reactive, when aluminum metal, calcium oxide and silicone oxide is kept in alkaline solution, $\mathrm{H}_{2}$ and carbon oxid gas is evolved and aluminum hydroxide is formed. Finally, molecules of carbon dioxid will be trapped in the geopolymer structure [42]. 

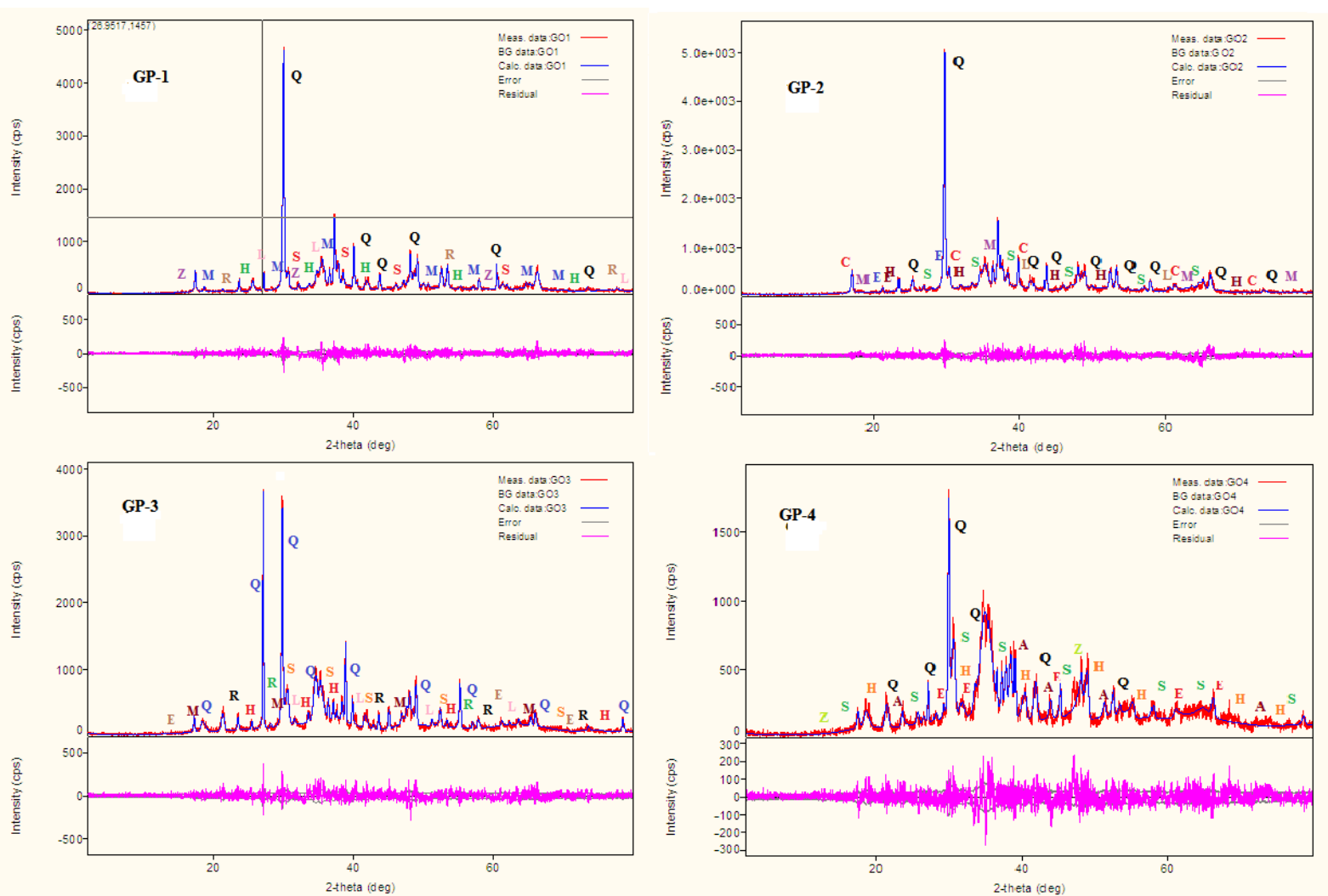

Figure 5.The XRD pattern of geopolymer (GP-1,GP-2,GP-3and GP-4) with $\mathrm{NaOH}$ molar ratio variation of $13 \mathrm{M}$.

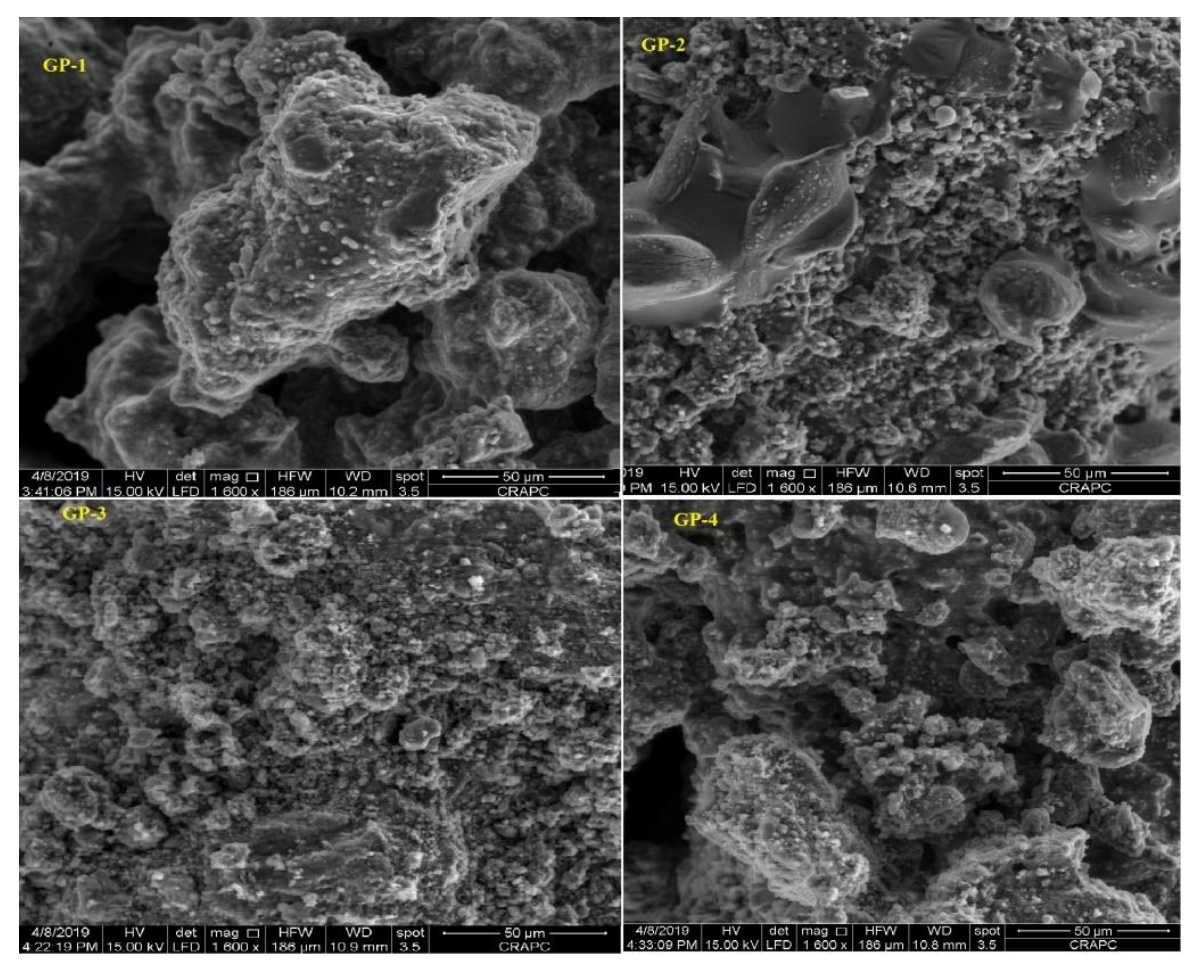

Figure 6.SEM micrographs of the geopolymer blocks vs. fly ash egg shell (FAES: Fly ash, GP-1, GP-2, GP-3, GP-4: 1 hours). 


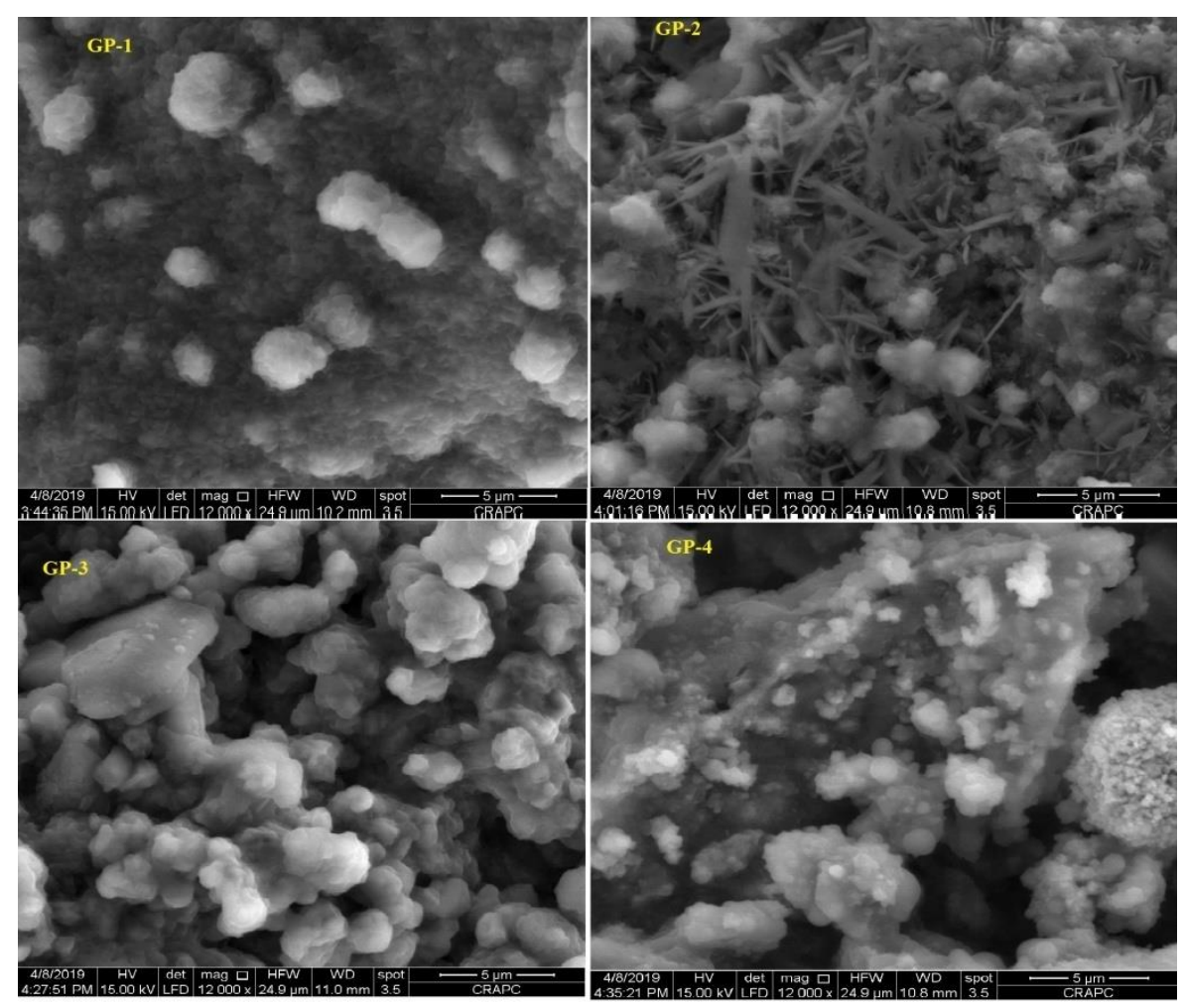

Figure 7.SEM micrographs of the geopolymer blocks vs. fly ash egg shell (FAES: Fly ash, GP-1, GP-2, GP-3, GP-4 :24 hours).

Moisture content of fly ash, sand dune and geopolymers synthesized were discussed. The percentage moisture retains of fly ash and sand dune and geopolymers are shown in (Figure 8). It was observed that moisture retain gradually. The decreases in moisture retain and water uptake can be attributed to the percentage of sand and fly ash in the matrix being limited, which reflects that the quantity of the geopolymer introduced in the layers reaches a limit and is enough to achieve maximum opening of the interlayer of fly ash and the formation of a cross-linked structure a certain extent which prevents the insert on of water molecules [43]. Finally, water resistance of these geopolymers which as defined the decreases in moisture retain and water uptake values can be greatly improved. To evaluate the effect of fly ash and sand dune in prepared geopolymers, we prepared seven samples with the same procedure. Compression tests were conducted using a LLoyd LR/10KN Universal Machine at room temperature and crosshead speed of $50 \mathrm{~mm}$ min-1for the determination of compression modulus and yield strength, according to the standard ASTM D638. Compared with geopolymers prepared by other alumino-silicates sources and under conventional method, the young's modulus and yield strength are greatly enhanced as shown in(Table 5 and 6). It shows that the mecanicals properties of geopolymers depend on the content of fly ash and molar ratio fly ash/sand dune [44]. The compression test was carried out to evaluate the compression properties of the various samples compositions in order to determine the influence of the addition of the fly ash on the compression properties of the virgin matrix [45]. Young modulus, compressive strength and elongation at break were evaluated as a function of the mass fraction of fly ash in all series of samples. The test pieces are maintained during the test by pneumatic jaws preventing any sliding of the test 
piece during the traction. The initial strain rate was set at $5 \mathrm{~mm} \mathrm{min-}{ }^{1}$. From these results, it can be deduced that the incorporation of the fly ash into the geopolymer matrix, with different percentages, has significantly improved all of its compression properties. Thus Young's modulus increased in compositions with the highest fly ash contents, (20-50 w $\%)$ [46]. The composition of fly ash $(10 \mathrm{w} \%)$ in geopolymer has the highest compression values. This is attributed to the interactions between the geopolymer chains and the nanometric layers of the fly ash with a decrease in the value of the Young's modulus. This composition is the most compressive resistant with a maximum stress of $49.71 \mathrm{MPa}$, the most flexible $(\mathrm{E}=2.63 \mathrm{GPa})$ and the most ductile $(\varepsilon \mathrm{r}=65.42 \%)$. This result confirms the exfoliation of fly ash in geopolymers synthesized (GP-1, GP-2, GP-3, GP-4, GP-5, GP-7) which is in agreement with the literature [47].

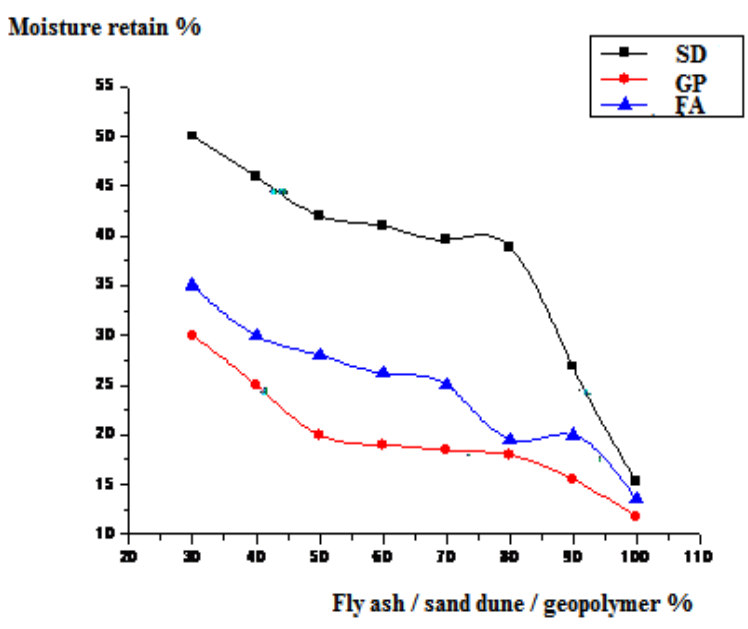

Figure 8.The percentage moisture retains values of fly ash, sand dune and geopolymer (GPs) obtained including different percentages of fly ash (FAES).

Table 5. Mechanical properties of fly ash, sand dune and geopolymers samples.

\begin{tabular}{cccccc}
\hline Sample & $\begin{array}{c}\text { Fly ash } \\
(\mathbf{\%})\end{array}$ & $\begin{array}{c}\text { Young's modulus } \\
(\mathbf{G P a})\end{array}$ & $\begin{array}{c}\text { Deformation } \\
\text { at break } \\
(\mathbf{\%})\end{array}$ & $\begin{array}{c}\text { Maximum stress } \\
(\mathbf{M P a})\end{array}$ & $\begin{array}{c}\text { Yield strength } \\
(\mathbf{M P a})\end{array}$ \\
\hline Sand dune & - & 0.86 & 20.09 & 15.33 & -- \\
\hline Fly ash & - & 1.43 & 37.95 & 31.06 & 75.25 \\
\hline $\begin{array}{c}\text { Fly } \\
\text { ash-NaOH }\end{array}$ & - & 1.72 & 42.01 & 39.82 & 70.94 \\
\hline GP-1 & 5 & 1.75 & 45.21 & 41.09 & 70.66 \\
\hline GP-2 & 10 & 1.96 & 49.97 & 49.71 & 80.94 \\
\hline GP-3 & 20 & 1.85 & 49.61 & 47.45 & 79.19 \\
\hline GP-4 & 30 & 1.73 & 48.05 & 45.59 & 78.10 \\
\hline GP-5 & 40 & 1.71 & 47.43 & 42.36 & 75.06 \\
\hline GP-7 & 50 & 1.52 & 45.31 & 40.24 & \\
\hline
\end{tabular}

Table 6.Tension strength of different geopolymers synthesized (GPs).

\begin{tabular}{cc}
\hline Geopolymers & Tension at 28 days $\left(\mathbf{k N} / \mathbf{m m}^{2}\right)$ \\
\hline GP-1 & 1.88 \\
\hline GP-2 & 2.1 \\
\hline GP-3 & 1.74 \\
\hline GP-4 & 1.59 \\
\hline GP-5 & 1.46 \\
\hline
\end{tabular}




GP-7 1.42

\section{Conclusion}

This study describes the valorization of raw and actived fly ash of eggs shell and algerian sand dune for preparation of geopolymers mortars (cementitious materials). The first step of preparing $\mathrm{SiO}_{2}$ from sand include sand obtained with size less than 100 microns by washing with an alkali and hydrochloric acid $(\mathrm{HCl})$ followed by washing with distilled water. The sand particles are then dried at room temperature. Sodium silicate $\left(\mathrm{Na}_{2} \mathrm{SiO}_{3}\right)$ was prepared by alkaline activation and characterized in our laboratory. The chemical composition by XRF indicate that sand dune (southern of Algeria) deposit has a high concentration of quartz (90.04 to $99.16 \%$ silica) with low concentration of others oxides. The microscopic observations reveals several morphologies of sand, some are elongated, rounded and angular with presence of pores. The fly ash of eggs shell exhibit better performance than ordinary cements on water penetration, very good fire resistance and minimize carbon dioxid $\left(\mathrm{CO}_{2}\right)$. The micro structure and the SEM results reveal that the egg shell is properly and evenly distributed in the matrix phase and has a good bonding between the egg shell particles and sand dune rich in silicium and aluminum. The geopolymers resulting from the eggs shell fly ashes and sand dune exhibit an amorphous character in general and it is determined that fly ash can be successively used with sand dune for achieving green and durable concrete.

\section{Acknowledgements}

We thank all staff of research center in physico-chemicals analysis (CRAPC) of Tipaza for their kind cooperation and characterization (XRF, X-ray,SEM ). Funding for this work was provided by the General Direction of research and development technologies/Ministry of Higher Education and Research DGRSDT/MERS (ALGERIA).

\section{References}

[1]. Ferone, C., Capasso, I., Bonati, A., Roviello, G., Montagnaro, F., Santoro, L., Turco, R., Cioffi, R. (2019). Sustainable management of water potabilization sludge by means of geopolymers production. Journal of Cleaner Production, 229, 1-9.

[2]. Capasso, I., Lirer, S., Flora, A., Ferone, C., Cioffi, R., Caputo, D., Liguori, B. (2019). Reuse of mining waste as aggregates in fly ash-based geopolymers. Journal of Cleaner Production, 220, 65-73.

[3]. Alireza, N.G., Suraya, A.R., Farah, N., Mohamad, A.S,.2010. Assessment of the effects of rice husk ash particle size on strength, water permeability and workability of binary blended concrete. Construction and Building Materials 24, 2145-2150.

[4]. Akinyemi S.A., Akinlua, A., Gitari, W.M., Nyale SM, Akinyeye, R.O., Petrik, L.F.,2012. An Investigative Study on the Chemical, Morphological and Mineralogical Alterations of Dry Disposed Fly Ash during Sequential Chemical Extraction. Energy Science and Technology. 3, 28 - 37. 
[5]. Al Bakri, A.M.M., Kamarudin, H., Binhussain, M., Khairul, N.I., Zarina, Y.,Rafiza, A.R., 2011.The Effect of Curing Temperature on Physical and Chemical Properties of Geopolymers.Physics Procedia.22, 286-291

[6]. Arun Kumar, M.B., Swamy, R.P., 2011. Evaluation of mechanical Properties of Al 6061, Fly ashand E-Glass Fiber Reinforced Hybrid Metal Matrix Composites. ARPN Journal of Engineering and Applierd Sciences 6 (5), 40-44.

[7]. Buchwald, A., Hohmann, M., Posern, K.,Brendler, E.,2009. The suitability of thermally activated illite/smectite clay as raw material for geopolymer binders. Appl. Clay. Sci. 3, 300-304.

[8]. Babajide, O., Petrik, L., Musyoka, N., Amigun, B., Ameer, F.,2010. Use of coal fly ash as a catalyst in the production of biodiesel.Petroleum\& Coal.52, $261-272$.

[9]. Chindaprasirt, P., Rukzon, S,. 2008. Strength, porosity and corrosion resistance of ternary bland Portland cement.rice husk and fly ash mortar. Construction and Building Materials $22,1601-1606$.

[10]. Chindaprasirt, P.,Kanchanda, P., Sathonsaowaphak, A., Cao,H.T., 2007. Sulfate resistance of blended cement containing fly ash and rice husk ash. Construction and Building Materials. 21, 1356-1361.

[11]. Cioffi, R., Maffucci, L., Santoro, L., 2003.Optimization of geopolymer synthesis by calcination and polycondensation of a kaoliniticresidue.Resour. Conserv.Recy. 40, 27-38.

[12]. Ferone, C., Colangelo, F.,Cioffi, R., Montagnaro, F.,Santoro, L.,2013. Use of reservoir clay sediments as raw materials for geopolymer binders. Adv. Appl. Ceram. 112, 184-189.

[13]. Ferone, C., Colangelo, F., Messina, F., Santoro, L.,Cioffi, R.,2013. Recycling of pre-washed municipal solid waste incinerator fly ash in the manufacturing of low temperature setting geopolymer. Materials 6, 3420-3437.

[14]. Filho, J.H., Medeiros, M.H.F., Pereir, E., Helene, P., Isaia, G.C., 2013. High Volume Fly Ash Concrete with and without Hydrated Lime: Chloride Diffusion Coefficient from Accelerated Test. Journal of Materials in Civil Engineering. 25, 411-418.

[15]. Ganesan, K., Rajagopal,K., Thangavel, K., 2008. Rice husk ash blended cement: Assessment of optimal level of replacement for strength and permeability properties of concrete". Construction and Building Materials 22, 1675-1683.

[16]. Glasby, T., Day, J., Genich, R., Kemp, M., 2015. Commercial scale geopolymer concrete construction. Proceedings of the saudi international building and constructions technology conference.

[17]. Ghosal, S., Self S.A., 1995. Particle size-density relation and cenosphere content of coal fly ash. Fuel. 74, 522 - 529.

[18]. Hassan, S.B., Aigodion, V.S., 2015. Effects of egg shell on the microstructures and properties of Al-Cu-Mg/egg shell particulate composites.Journal of King Saud University Engineering Sciences.27, 49-56

[19]. Moreno, N., Querol, X., Andrés J.M., Stanton, K., Towler, M., Nugteren, H., Janssen-Jurkovicová, M., Jones, R.,2005. Physico-chemical characteristics of European pulverized coal combustion fly ashes. Fuel.84, 1351-1363. 
[20]. Mathur, V.K.,Verma, C.L., Gupta, B.S., Agarwal, S.K., Awadesh K., 2005. Use of Higher Volume Fly ash in Concrete for Building Sector. Report No.T(S) 006, CII CANMET-CIDA, HVFA, Project. Environmental Science and Technology Division, Roorkee.

[21]. Mishra, A., Choudhary, D., Jain, N., Kumar, M., Sharda N., Dutt, D.,2008. Effect of concentration of alkaline liquid and curing time on strength and water absorption of geopolymerconcrete.ARPN Journal of Engineering and Applied Sciences.3, 14.

[22]. OlajideOdewale, I., OluseguAjala, L., Tse. D.T., 2013. Characterizaton of Unwana Beach Silica Sand and its Industrial Applications. International Journal of Science Innovations and Discoveries. 3, 93 - 100.

[23]. Onera,A., Akyuzb, T.S., Yildiza,R., 2005. An experimental study on strength development of concrete containing fly ash and optimum usage of fly ash in concrete. Cement and Concrete Research 35, 1165- 1171

[24]. Perruchoud, R., Fischer, J.C., 2017. High Purity Composite Briquette for Direct UMGSi Production in Arc Furnaces. Journal of Siberian Federal University. Chemistry 10, 58-66

[25]. Palomo A.,Grutzeck M.W., Blanco M.T. 1999. Alkali-activated fly ashes: A cement for the future. Cement and Concrete Research. 29(8),1323-1329.

[26]. Papadakis, V.G., 1999. Effect of Fly Ash on Portland Cement Systems Part-I: Low Calcium Fly Ash. Cement and Concrete Research. 29, 1727-1736 .

[27]. Quercia, G., Van Der Putten,J.J.G.,Hüskenc, G.,Brouwers,H.J.H., 2013.Photovoltaic's Silica-Rich Waste Sludge as Supplementary Cementitious. Cement and Concrete Research, 54, 161-179.

[28]. Andini, S., Cioffi, R., Colangelo, F., Grieco, T., Montagnaro, F., Santoro, L., 2008.Waste Manage. Coal fly ash as raw material for the manufacture of geopolymer-based products. Waste Management. 28, 416-423

[29]. Rickard, W.D.A., Williams, R., Jadambaa, T., Van Riessen, A.,2011. the suitability of three australian fly ashes as an aluminosilicate source for geopolymers in high temperature applications. Mat. Sci. Eng. 528, 3390-3397.

[30]. Shi, C., Krivenko, P., Roy, D.,2006. Alkali-Activated Cements and Concretes; Taylor and Francis. Abington, UK.

[31]. Skavara, F., Kopecky, L., Nemecek, J., Bittnar, Z., 2006. Microstructure of geopolymer materials based on fly ash.Ceramics-Silikaty.50, 208-215

[32]. Siva Prasad, D., Rama Krishna, A., 2011. Production and Mechanical Properties of A356.2/RHA Composite.International Journal of Advanced Science and technology. 33,51-58.

[33]. Skavara, F., Jilek, T., Kopecky, L., 2005. Geopolymer Materials Based on Fly Ash. Ceramics-Silicaty. 49(3), 195-204.

[34]. Soma, N.J., Chandrasekhar, 2015. A Comparative Study on Egg Shell Concrete with Partial Replacement of Cement by Fly Ash.International Journal for Research in Applied Science \& Engineering Technology (IJRASET).Volume 3, Special Issue-I1. 
[35]. Tsong, Y., Tsao-Hua, H., Yu-Wen, L., Shin-Ho, C., 2007. Influence of class F fly ash on the abrasion-erosion resistance of high-strength concrete. Construction and Building Materials. 21, 458-463.

[36]. Tangstad,M.,Ferrosilicon an Silicon Technology. Norwegian University of Science and Technology. Trondheim, Norway. 2013.

[37]. Van Riessen, A., Chen-Tan, N., 2013.Beneficiation of collie fly ash for synthesis of geopolymer, part 1 - beneficiation. Fuel. 106, 569 - 575.

[38]. Varughese, K.T., Chaturvedi, B.K., 1996. Fly Ash as Fine Aggregate in Polyester Based Polymer Concrete. Cement\&Concrete Composites. 18 105-108.

[39]. Xu, H.,Van Deventer, J.S.J.,2000. The geopolymerisation of alumino-silicate minerals.International Journal of Mineral Processing.59, 247-266.

[40]. Xu, H., Van Deventer, J.S.J., 2003. Effect of source materials onGeopolymerization. Ind. Eng. Chem. Res., 42(8) 1698-1706.

[41]. Williams, R., Van Riessen, A., 2010. Determination of the reactive component of fly ashes for geopolymer production using XRF and XRD, Fuel. 89, 3683 - 3692.

[42]. Shi, C.; Krivenko, P.V.; Roy, D.M. Alkali-Activated Cements and Concretes; Taylor and Francis: Abington, UK, 2006.

[43]. Ferone, C.; Colangelo, F.; Cioffi, R.; Montagnaro, F.; Santoro, L. Use of reservoir clay sediments as raw materials for geopolymer binders. Adv. Appl. Ceram. 2013, 112, 184-189.

[44]. Arun Kumar, M.B., Swamy, R.P., 2011. Evaluation of mechanical Properties of Al 6061, Fly ashand E-Glass Fiber Reinforced Hybrid Metal Matrix Composites. ARPN Journal of Engineering and Applierd Sciences 6 (5), 40-44.

[45]. Akinyemi SA, Akinlua A, Gitari WM, Nyale SM, Akinyeye RO, Petrik LF. An Investigative Study on the Chemical, Morphological and Mineralogical Alterations of Dry Disposed Fly Ash during Sequential Chemical Extraction. Energy Science and Technology 2012;3:28 - 37.

[46]. G. Quercia, J.J.G. van der Putten, G. Hüskenc and H.J.H. Brouwers, 'Photovoltaic's Silica-Rich Waste Sludge as Supplementary Cementitious', Cement and Concrete Research, Vol. 54, pp. 161 - 179, 2013.

[47]. R. Perruchoud and J.C. Fischer, 'High Purity Composite Briquette for Direct UMGSi Production in Arc Furnaces', R\&D Carbon Ltd, CH-3960 Sierre, Switzerland, 2014. 